\title{
Stability of Eosinophilic Inflammation in COPD Bronchial Biopsies
}

DOI:

10.1183/13993003.00622-2020

\section{Document Version}

Accepted author manuscript

Link to publication record in Manchester Research Explorer

\section{Citation for published version (APA):}

Higham, A., Leow-Dyke, S., Jackson, N., \& Singh, D. (2020). Stability of Eosinophilic Inflammation in COPD Bronchial Biopsies. European Respiratory Journal. https://doi.org/10.1183/13993003.00622-2020

\section{Published in:}

European Respiratory Journal

\section{Citing this paper}

Please note that where the full-text provided on Manchester Research Explorer is the Author Accepted Manuscript or Proof version this may differ from the final Published version. If citing, it is advised that you check and use the publisher's definitive version.

\section{General rights}

Copyright and moral rights for the publications made accessible in the Research Explorer are retained by the authors and/or other copyright owners and it is a condition of accessing publications that users recognise and abide by the legal requirements associated with these rights.

\section{Takedown policy}

If you believe that this document breaches copyright please refer to the University of Manchester's Takedown Procedures [http://man.ac.uk/04Y6Bo] or contact uml.scholarlycommunications@manchester.ac.uk providing relevant details, so we can investigate your claim.

\section{OPEN ACCESS}


1 Stability of Eosinophilic Inflammation in COPD Bronchial Biopsies

2 Andrew Higham ${ }^{1}$, Sophie Leow-Dyke², Natalie Jackson ${ }^{2}$ and Dave Singh ${ }^{1,2}$

3 1. Division of Infection, Immunity and Respiratory Medicine, School of Biological Sciences,

4 Faculty of Biology, Medicine and Health, Manchester Academic Health Science Centre, The

5 University of Manchester and Manchester University NHS Foundation Trust, Manchester, UK.

6 2. Medicines Evaluation Unit, The Langley Building, Southmoor Road, Manchester, UK.

7

8 Corresponding Author:

9 Andrew Higham

10 Telephone: +441612914050

11 E-mail: Andrew.Higham@manchester.ac.uk

Manuscript word count $=1194$ 
2 Blood eosinophil counts (BEC) predict the response to inhaled corticosteroids (ICS) in COPD 3 patients with increased exacerbation risk ${ }^{12}$. Studies have shown an association between BEC

4 and both sputum and lung tissue eosinophil counts in COPD patients ${ }^{34}$, supporting BEC as a 5 biomarker that reflects the degree of eosinophilic lung inflammation. While the long-term 6 stability of BEC in COPD patients has been studied ${ }^{5-7}$, the stability of eosinophilic airway 7 inflammation in COPD patients is less clear. Good stability of COPD sputum eosinophil counts 8 up to 3 months has been reported ${ }^{89}$, but similar analysis using sub-mucosal eosinophil counts 9 (SMEC) are lacking.

We assessed COPD SMEC stability using samples from repeat bronchoscopies. We also analysed SMEC variability using sections from the same bronchoscopy, and investigated the relationship between BEC and SMEC.

Bronchial biopsies were obtained from 28 COPD patients; 14 had $\geq 2$ bronchoscopies. The inclusion criteria were; age $>40$ years, $>10$ pack-year smoking history, a post-bronchodilator forced expiratory volume in 1 second $\left(\mathrm{FEV}_{1}\right) /$ forced vital capacity $(\mathrm{FVC})$ ratio of $<0.7$, and no history of asthma. Bronchoscopies were performed at least 6 weeks after a respiratory infection. Eight patients were female (29\%), the mean age was 64 years, mean $\mathrm{FEV}_{1}$ predicted was $62 \%$, 17 patients (61\%) used ICS, 15 patients used LABA (54\%), 9 patients used LAMA (32\%) and 17 patients were current smokers. The mean exacerbation frequency (an exacerbation was defined as a COPD worsening that required a course of oral corticosteroids and / or antibiotics, or caused hospitalisation) was 1.5 in the previous 12 months, and the mean CAT score was 13. The mean bronchodilator reversibility was $214 \mathrm{ml}$ (15\%). All patients were atopy negative and one patient had a rhinitis history. Blood immunoglobulin $E$ 
1 measurements were not available. This study was conducted in accordance with the

2 amended Declaration of Helsinki. Local research ethics committees approved the study and

3 patients provided written informed consent.

4 Bronchial biopsy analysis was conducted in three parts. Part 1 assessed intra-biopsy (within biopsy) SMEC variability. Part 2 assessed inter-biopsy (between biopsy) SMEC variability from

6 the same bronchoscopy. Part 3 assessed intra-patient variability of SMEC over time from 7 repeated bronchoscopies. Eosinophils were identified using the modified LUNA stain ${ }^{3}$. Blood 8 eosinophil counts were collected where available $(n=12)$.

9 Intraclass correlation coefficients (ICC) were calculated; these are interpreted as excellent $(>0.75)$, fair to good $(0.40-0.75)$ or poor $(<0.40){ }^{10}$. Bland-Altman analysis examined the level of agreement (LOA) of SMEC between sections (part 1), between biopsies (part 2) and between visits (part 3). The mean difference and the LOA (mean difference plus or minus 1.96 X standard deviation (SD) of the difference, equivalent to $z$-score) were calculated. Spearman correlation was used to assess relationship between BEC and SMEC. $\mathrm{P}<0.05$ was considered statistically significant.

Part 1: Up to 4 sections from 12 COPD patients (9 patients had 3 sections and 3 patients had 4 sections) were obtained; mean counts for sections 1 to 4 were 36.3, 34.0, 20.4 and 15.5 eosinophils $/ \mathrm{mm}^{2}$ respectively. The intra-patient standard deviation (SD) was 14.2 eosinophils $/ \mathrm{mm}^{2}$ and the ICC was 0.87 .

Bland-Altman analysis demonstrated a mean difference of 13.0 and LOA -61.1 and 87.1 eosinophils $/ \mathrm{mm}^{2}$ (figure $1 \mathrm{~A}$ ). Visual inspection of the plot indicates greater mean differences at higher SMEC. To analyse this further, an arbitrary cut-off (20 eosinophils $/ \mathrm{mm}^{2}$ ) was used to divide the cohort into eosinophil ${ }^{\text {low }}$ (mean difference 4.3; LOA -14.7 and 23.3 
1 eosinophils $/ \mathrm{mm}^{2}$ ) and eosinophil ${ }^{\text {high }}$ (mean difference 33.1 and wider LOA of -94.2 and 160.3

2 eosinophils $/ \mathrm{mm}^{2}$ ) patients. The mean intra-patient SD of the eosinophil ${ }^{\text {low }}$ and eosinophil ${ }^{\text {high }}$

3 groups were 4.7 and 33.2 eosinophils $/ \mathrm{mm}^{2}$ respectively.

4 Part 2: Samples from 19 COPD patients were used; $n=7$ had 2 biopsies, $n=10$ had 3 biopsies

5 and $n=2$ had 4 biopsies. The group mean counts for biopsies 1 to 4 were 22.2, 30.0, 17.9 and

652.1 eosinophils $/ \mathrm{mm}^{2}$ respectively. The mean intra-patient SD was 17.3 eosinophils $/ \mathrm{mm}^{2}$ and

7 the ICC was 0.72.

8 Bland-Altman analysis showed a mean difference of 5.7 and LOA -61.8 and 73.3

9 eosinophils $/ \mathrm{mm}^{2}$. Variability was reduced in eosinophil low patients (mean difference 3.3; LOA

$10-22.9$ and 29.5; SD 7.8; units = eosinophils $/ \mathrm{mm}^{2}$ ) compared to eosinophil ${ }^{\text {high }}$ patients (mean

11 difference 8.6; LOA of -89.1 and 106.2; SD 25.9; units = eosinophils $/ \mathrm{mm}^{2}$ ). The precise

12 location of each biopsy was not available.

13 Part 3: 14 COPD patients had repeat bronchoscopies, ranging from 1 month to 3 years apart

14 (median 9 months; $n=14$ had 2 visits and $n=6$ had 3 visits). The group mean counts from visits 1 to 3 were 20.5, 41.0 and 63.4 eosinophils $/ \mathrm{mm}^{2}$ figure $1 B$ ). The mean intra-patient SD was 23.0 eosinophils $/ \mathrm{mm}^{2}$ and the ICC was 0.66 .

Bland-Altman analysis showed a mean difference of 30.7 and LOA -85.8 and 147.2 eosinophils $/ \mathrm{mm}^{2}$ (figure $1 \mathrm{C}$ ). Variability was reduced in eosinophilow patients (mean difference 2.6; LOA -10.9 and 16.2; SD 4.3; units = eosinophils $/ \mathrm{mm}^{2}$ ) compared to eosinophil $^{\text {high }}$ patients (mean difference 51.6; LOA -94.7 and 197.9; SD 30.5; units = 21 eosinophils $/ \mathrm{mm}^{2}$ ). 
1 Blood eosinophil counts were available for at least one of the visits for 12 out of the 14

2 patients $(n=20$ data points in total; median $=400$ eosinophils $/ \mu \mathrm{L}, \mathrm{n}=2$ were $<100$

3 eosinophils $/ \mu \mathrm{L}, \mathrm{n}=7$ were between $100-300$ eosinophils $/ \mu \mathrm{L}, \mathrm{n}=11$ were $>300$

4 eosinophils $/ \mu \mathrm{L}$ ); blood and tissue eosinophil numbers were correlated (figure 1D R=0.7 and

$5 \mathrm{p}=0.001)$.

6 We assessed SMEC variability in COPD patients. ICC analysis demonstrated excellent 7 correlation ( 0.87 ) between results from the same biopsy (part 1$)$, and good correlation ( 0.72 ) 8 between different biopsies from the same bronchoscopy (part 2) and repeated 9 bronchoscopies (0.66; part 3). In all 3 parts, Bland-Altman analysis demonstrated greater variability in patients with higher SMEC. The results of parts 1,2 and 3 taken together indicate that higher SMEC are associated with increased variation regionally (within the bronchial tree) and over time, in contrast to lower SMEC counts which show less regional and temporal variation.

Previous studies have reported associations between BEC and both sputum and lung eosinophil counts ${ }^{411}$, although negative results have also been reported ${ }^{12}$. Our results show a good correlation between SMEC and BEC, providing further evidence that BEC reflect the extent of pulmonary eosinophilic inflammation in COPD patients.

COPD BEC studies have shown that lower BEC show good stability over time, with increased variability at higher BEC ${ }^{5}$ 7. We now show the same pattern for SMEC, while also demonstrating an association between BEC and SMEC. Overall, these observations suggest that the stability of BEC and SMEC behave in a similar manner. Inflammation involves dynamic processes, including cell recruitment and activation; these BEC and SMEC observations suggest that the presence of higher levels of eosinophilic airway inflammation (in the blood 
1 and lungs) is prone to dynamic fluctuation over time. Furthermore, with reference to the use

2 of BEC to predict the effects of ICS in COPD patients, our results support BEC as a biomarker

3 which (i) reflect the degree of eosinophilic lung inflammation and (ii) shows a similar pattern

4 of variation over time compared to SMEC.

5 In conclusion, the presence of lower levels of submucosal eosinophilic airway inflammation

6 in COPD patients is relatively homogeneous throughout the bronchial tree and highly stable

7 over time. In contrast, the presence of higher levels of eosinophilic airway inflammation is

8 more heterogeneous throughout the bronchial tree, and shows increased biological variation

9 over time.

10 
2 This research was co-funded by the NIHR Manchester Biomedical Research Centre and the

3 North West Lung Centre Charity, Manchester. This report is independent research and the

4 views expressed in this publication are those of the authors and not necessarily those of the 5 NHS, the NIHR or the Department of Health.

7 FIGURE LEGEND

Figure 1. Sub-mucosal eosinophil counts from COPD bronchial biopsies. (A) Bland-Altman analysis from part 1 shows the mean eosinophil count from section 1 vs section 2/3/4 from each patient plotted against the difference in eosinophil count of section 1 vs section 2/3/4 from each patient. Data plotted for all patients. The middle dashed line represents the mean difference of the data and the top and bottom dashed lines represent the limits of agreement. Vertical red line indicates threshold at 20 eosinophils $/ \mathrm{mm}^{2}$. (B) Eosinophil numbers were quantified from bronchial biopsies obtained during repeat bronchoscopies (part 3). Individual patients are presented $(1-14)$ and each data point represents the mean count taken from two sections; different symbols (black circles and red triangles) are used alternately to enable clearer interpretation. The maximal difference between mean counts for each patient is represented at the top of the graph. (C) Bland-Altman analysis from part 3 shows the mean eosinophil count from bronchoscopy 1 vs bronchoscopy $2 / 3$ from each patient is plotted against the difference in eosinophil count of bronchoscopy 1 vs bronchoscopy $2 / 3$ from each patient. Data plotted for all patients. (D) Correlation between blood eosinophils and submucosal eosinophils ( $\mathrm{n}=20$ data points). 
1. Singh D, Agusti A, Anzueto A, et al. Global Strategy for the Diagnosis, Management, and Prevention of Chronic Obstructive Lung Disease: the GOLD science committee report 2019. Eur Respir J 2019;53(5) doi: 10.1183/13993003.00164-2019

2. Bafadhel $M$, Peterson $S$, De Blas $M A$, et al. Predictors of exacerbation risk and response to budesonide in patients with chronic obstructive pulmonary disease: a post-hoc analysis of three randomised trials. Lancet Respir Med 2018;6(2):117-26. doi: 10.1016/S22132600(18)30006-7

3. Kolsum U, Damera G, Pham TH, et al. Pulmonary inflammation in patients with chronic obstructive pulmonary disease with higher blood eosinophil counts. I Allergy Clin Immunol 2017;140(4):1181-84 e7. doi: 10.1016/j.jaci.2017.04.027

4. Eltboli O, Mistry V, Barker B, et al. Relationship between blood and bronchial submucosal eosinophilia and reticular basement membrane thickening in chronic obstructive pulmonary disease. Respirology 2015;20(4):667-70. doi: 10.1111/resp.12475

5. Southworth T, Beech G, Foden P, et al. The reproducibility of COPD blood eosinophil counts. Eur Respir J 2018;52(1) doi: 10.1183/13993003.00427-2018

6. Landis SH, Suruki R, Hilton E, et al. Stability of Blood Eosinophil Count in Patients with COPD in the UK Clinical Practice Research Datalink. COPD 2017;14(4):382-88. doi: 10.1080/15412555.2017.1313827

7. Long GH, Southworth $\mathrm{T}$, Kolsum $\mathrm{U}$, et al. The stability of blood Eosinophils in chronic obstructive pulmonary disease. Respir Res 2020;21(1):15. doi: 10.1186/s12931-020-1279-4

8. Boorsma M, Lutter R, van de Pol MA, et al. Repeatability of inflammatory parameters in induced sputum of COPD patients. COPD 2007;4(4):321-9. doi: 10.1080/15412550701597720

9. Brightling CE, Monterio W, Green RH, et al. Induced sputum and other outcome measures in chronic obstructive pulmonary disease: safety and repeatability. Respir Med 2001;95(12):999-1002. doi: 10.1053/rmed.2001.1195

10. Koo TK, Li MY. A Guideline of Selecting and Reporting Intraclass Correlation Coefficients for Reliability Research. J Chiropr Med 2016;15(2):155-63. doi: 10.1016/j.jcm.2016.02.012

11. Kolsum U, Donaldson GC, Singh R, et al. Blood and sputum eosinophils in COPD; relationship with bacterial load. Respir Res 2017;18(1):88. doi: 10.1186/s12931-017-0570-5

12. Turato G, Semenzato U, Bazzan E, et al. Blood Eosinophilia Neither Reflects Tissue Eosinophils nor Worsens Clinical Outcomes in Chronic Obstructive Pulmonary Disease. Am J Respir Crit Care Med 2018;197(9):1216-19. doi: 10.1164/rccm.201708-1684LE 
(A)

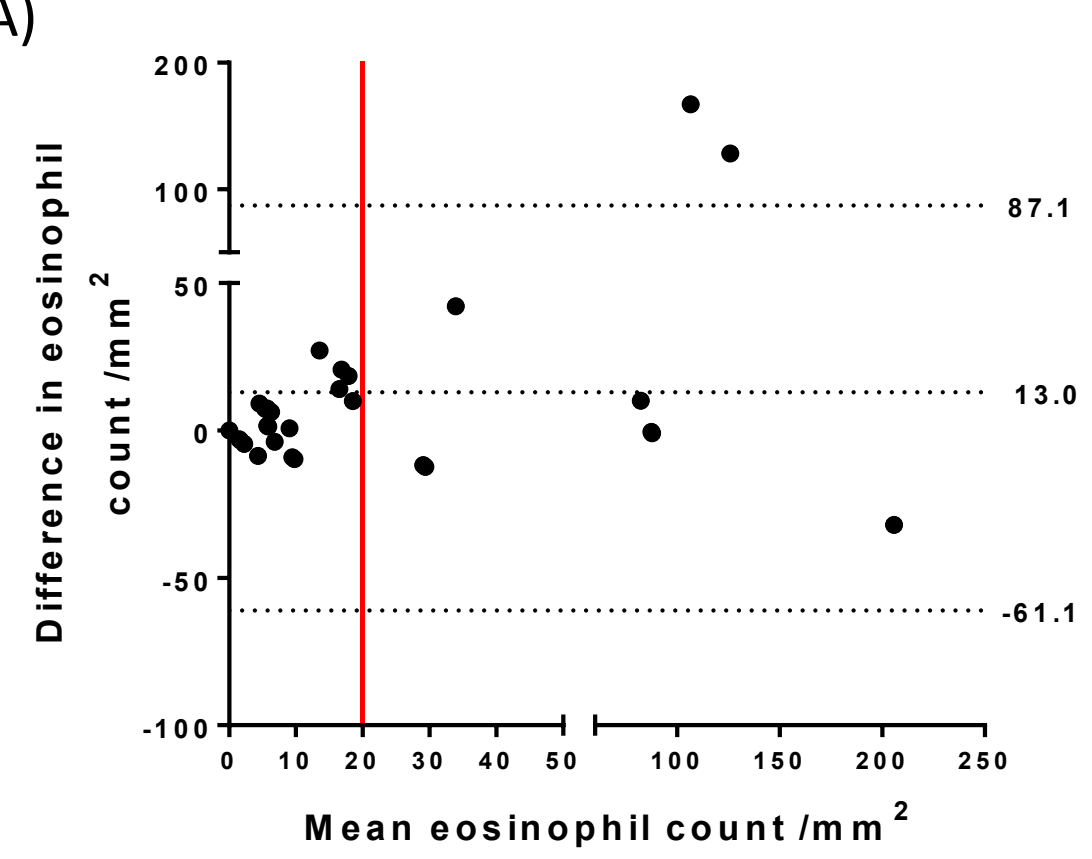

(C)

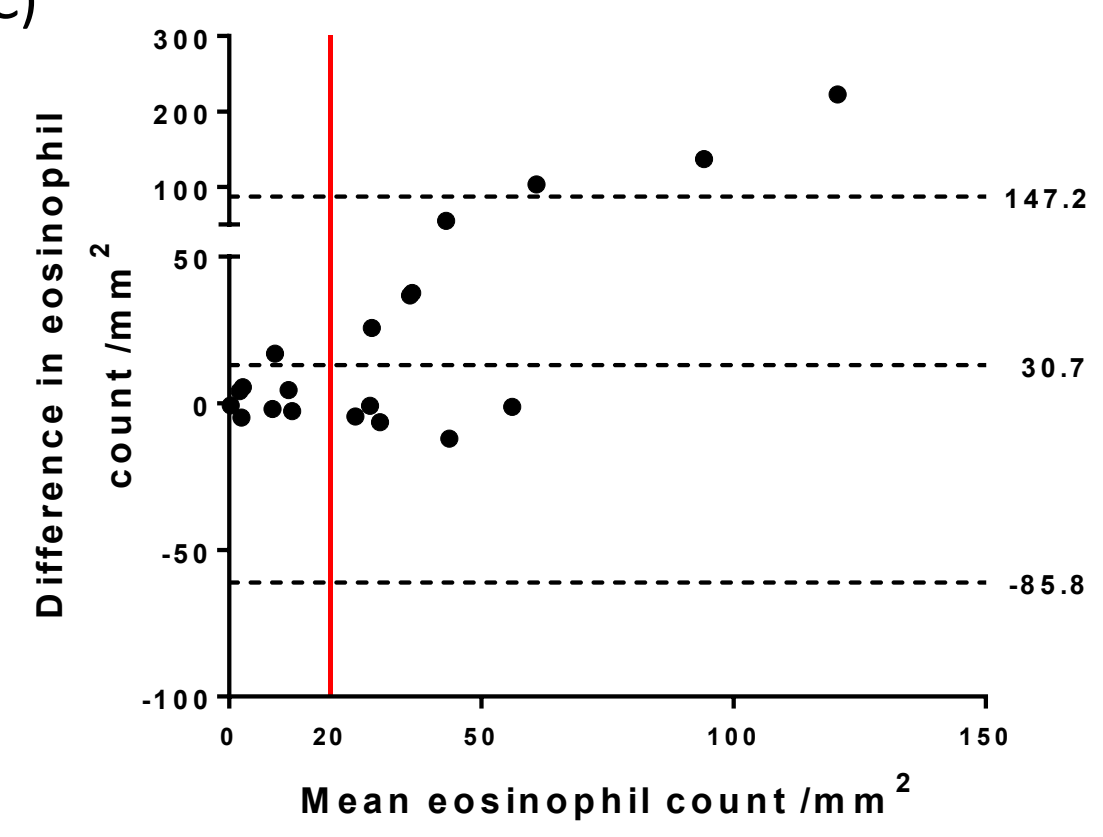

(B)

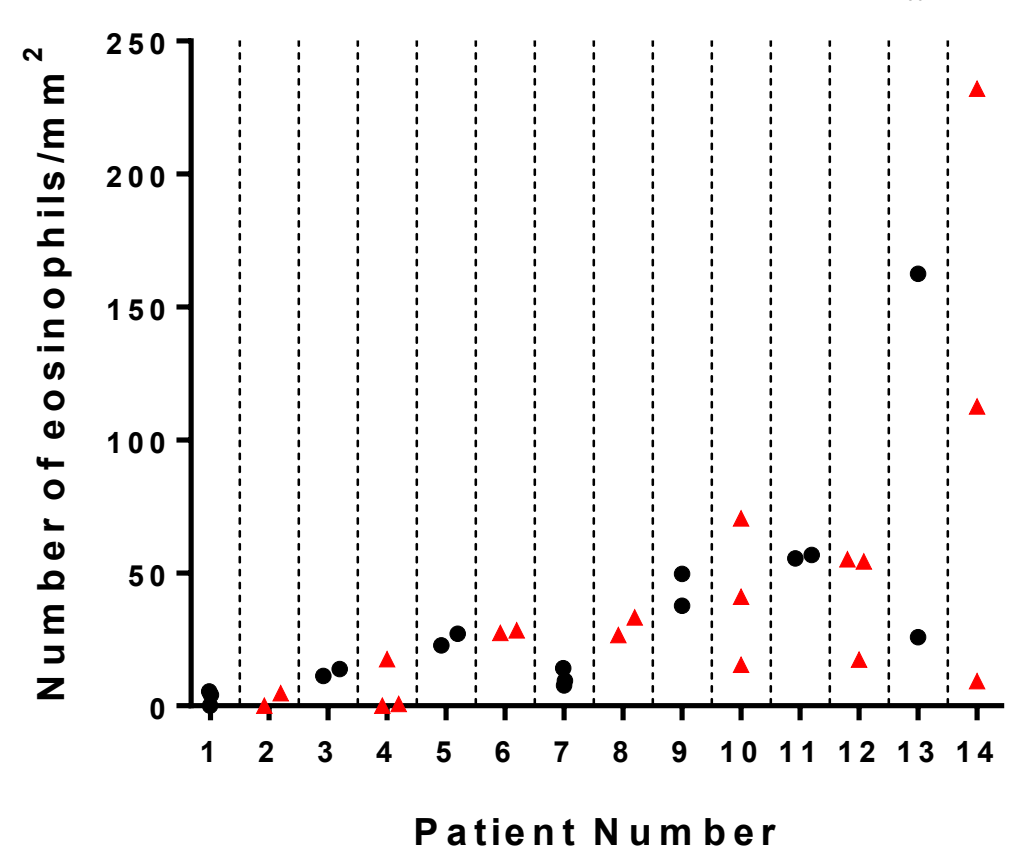

(D)

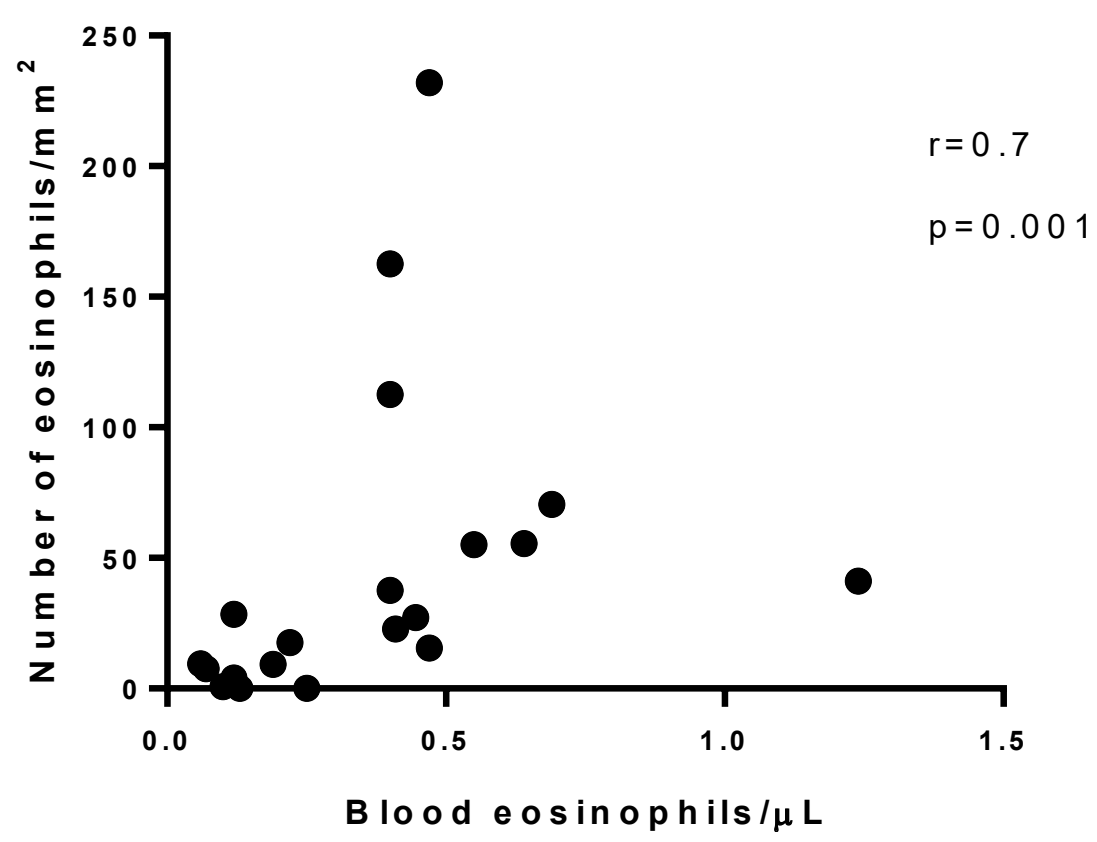

